\title{
Human Development Index, ICT, and Renewable Energy-Growth Nexus for Sustainable Development: A Novel PVAR Analysis
}

\begin{abstract}
Anam Azam ${ }^{1}$, Muhammad Rafiq ${ }^{2}$, Muhammad Shafique $^{3}$, Jiahai Yuan ${ }^{1,4 \star}$ and Sultan Salem ${ }^{5}$
${ }^{1}$ School of Economics and Management, North China Electric Power University, Beijing, China, ${ }^{2}$ Department of Electrical Engineering, University of Engineering and Technology, Taxila, Pakistan, ${ }^{3}$ Department of Architecture and Civil Engineering, City University of Hong Kong, Kowloon Tong, Hong Kong, ${ }^{4}$ Beijing Key Laboratory of New Energy and Low-Carbon Development, North China Electric Power University, Beijing, China, ${ }^{5}$ Department of Economics, Birmingham Business School, University of Birmingham, Birmingham, United Kingdom
\end{abstract}

The relevance of information and communication technology to long-lasting human improvement cannot be disregarded in this modern world. From this perspective, this study analyzed the association between information and communication technologies, renewable energy, economic growth, and human development indices considering $\mathrm{CO}_{2}$ emissions and remittances from 1990 to 2017 in 30 developing countries by using the panel vector autoregressive (PVAR) model. The findings of the empirical investigation point to the considerable favorable relationship between information and communication technology, renewable energy, and economic growth with the human development index. The causality results suggest that there is bidirectional causality between renewable energy and the human development index. In addition, there is unidirectional causality from human development to information and communication technology. However, the study recommends implementing information and communication technology-related policies to trigger renewable energy for sustainable growth and the human development index.

Keywords: ICT, $\mathrm{CO}_{2}$ emissions, GDP, technological innovations, poverty

\section{INTRODUCTION}

Technological development is commonly known as the main driver in the socioeconomic development of the economies. Recently, enhanced technological advancement for information and communication technologies (ICTs) has been the primary transformer for development procedures (World Bank 2017). ICT has modernized societies worldwide and contributes almost in all undertakings of human life, such as energy, promoting economic growth, and improved development processes (Toader et al., 2018; Khan and Ju, 2019). Significant development of ICT has encouraged many researchers to investigate its importance, improvement of organizational effectiveness, and human development practices (Tyworth 2014). ICT plays a vital role in plummeting poverty not only by crafting new income sources and new employment opportunities but also by dropping the expense of needy individuals' admittance to well-being and instruction services (OECD 2010).

Abbreviations: $\mathrm{CO}_{2}$, carbon dioxide emissions; EU, European Union; GDP, gross domestic product; HDI, human development index; ICTs, information and communication technologies; MTOE, million tons of oil equivalent; KT, kilo tons; 2SLS, two-stage least squares; OECD, Organization for Economic Co-Operation and Development; PVAR, panel vector autoregressive model; $\mathrm{RE}$, renewable energy; R\&D, Research and Development; SGD, sustainable development goals. 
The major function of ICT for sustainable development cannot be ignored in the economics literature. The ICT industry is an imperative aspect of endurable development from an integrated perspective, as reported by international organizations like the United Nations, the International Telecommunications Union, the Organization for Economic Co-Operation and Development (OECD), and the World Bank (Toader et al., 2018). Moreover, the sustainable development notion covers the complex development of civilization from numerous perspectives such as economic, social, ecological, political, cultural, and spiritual, and all these constituents are crucial aspects that aim to accomplish elegant, sustainable, and inclusive growth (Azam et al., 2021). However, concerning the effect of ICT on energy consumption and the environment is an extensive argument. The energy is being produced and consumed by all sectors of technology including aerospace, the construction industry, the transportation industry, farming, mining, and the ICT sector. Recently, there has been a greater emphasis on universal environmental apprehensions about the looming threat of environmental change and an 'Earth temperature boost' (Zhang et al., 2021) (Kirikkaleli D. and Adebayo T. S., 2021, Kirikkaleli Dervis and Adebayo TomiwaSunday, 2021). The broad measure of carbon dioxide $\left(\mathrm{CO}_{2}\right)$ outflows is quickly growing, provoking $\mathrm{CO}_{2}$ discharges because of the gigantic utilization of non-renewable energy sources around the world.

Under such circumstances, ICT can play a fundamental role in uplifting technological constraints and facilitating the renewable energy phenomenon in tandem (Azam et al., 2021). Sustainable power assets have recently gained a great deal of significance because of the threat of depleting power resources that harm the climate. ICT evolution extensively persuades economic amplification and augments fuel efficiency and development potency by bolstering technology dispersion and modernism, boosting demand, and reducing invention charges (Solarin et al., 2019).

The United Nations sustainable development goals (SGD) proclamation highlights the importance of lowering ambient air pollution globally, restricting traditional energy's share of the energy mix and supplementing sustainable power sources. As a result, multiple nations are attempting to devise renewable energy solutions to regulate environmental deprivation to meet SDG's goals. As a result, it is projected that state power schemes will be aligned with the aims of upgrading environmental prominence and assuring long-term evolution. To achieve these goals, however, it is critical to support technological breakthroughs and technology transfer through global trade (Liddle 2018; Shahbaz and Sinha 2019), particularly from the standpoint of poor regions. Under these circumstances, ICT is vital in delivering technical services for sustainable economic development in both developed and developing countries.

Why did we select developing countries as the focus of our research? Developing countries are open nations that have swiftly incorporated poor economic growth, a low standard of living, and the lack of investment and technology. Recently, more than 170 developing nations are bestowed with natural resources, but low levels of growth and foundations of innovation inaugurate ineffective utilization of energy (X. Zhang et al., 2019). Over the past few decades, a large amount of energy has been splurged on economic development in developing countries, engrossing almost 74\% in the period between 2005 and 2030. Furthermore, the situation of the human development index is precarious in these countries. Educational disparity and rising global income are the key reasons to delay human development growth. Furthermore, these countries have huge and growing populations which cause heavy pressure on the atmosphere.

With this backdrop, given the potential of ICT in terms of availability of energy supply and economic development stability, establishing empirical analysis on the links between ICT, renewable energy growth, and human development index is critical for incorporating $\mathrm{CO}_{2}$ emissions and remittances in the context of developing countries. However, the goal of this study is to address this issue, which is still understudied. More precisely, with three contributions, we particularly fill a gap in the literature.

The fundamental contributions of this study are threefold: first, this is the first study of its kind in the context of developing counties, with the latest data from 1990 to 2017. Second, this study employs additional variables, including remittances and $\mathrm{CO}_{2}$ emissions, to elude omitted variable bias. Third, different from the available literature, our study employs a recent panel model, developed by Love and Zicchino, called the panel vector autoregressive model (PVAR); this model allows shock analysis and is beneficial for classifying possible policy effects (Canova and Ciccarelli 2013). Furthermore, causality correlation among indicators is another element determined in the selection of techniques.

The following is a summary of the remainder of this research: Section-II investigated past literature reviews, Section-III discusses data and the methodological framework, Section-IV discusses practical outcomes and debate, and Section-V concludes with policy implications.

\section{LITERATURE REVIEW}

The correlation between the use of renewable power, economic growth, ICT, and human development index (HDI) has been the subject of intense research. Although numerous empirical studies are analyzing "renewable energy growth", "HDI growth," and "ICT growth" relationship separately, no studies are exploring these links together.

This section will examine these relations separately. Prior research has mostly focused on the liaison between renewable energy usage and economic growth. For example, Azam et al. (2021) observed that renewable energy usage augments economic enlargement in newly industrialized nations. Similarly, other studies of (Azam et al., 2021; Rahman and Velayutham, 2020; Vural, 2020) found that renewable energy significantly influences economic growth (Inglesi-Lotz 2016) and explores the influence of clean energy usage on the economy for OECD by using the panel data method. The empirical findings reveal that renewable energy consumption's impact on economic growth is constructive and analytically important. Similarly, Bhattacharya et al. (2016) confirmed that renewable energy consumption improved economic growth from 1991 to 2012 for 38 high energyconsuming regions. 
TABLE 1 | Summary of the literature renewable energy consumption-economic growth and human development index nexus.

\begin{tabular}{|c|c|c|c|c|}
\hline Author(s) & Study area & Period & Methodology & Results \\
\hline $\begin{array}{l}\text { Shahbaz, Lean, and Shabbir } \\
\text { (2012) }\end{array}$ & Pakistan & $\begin{array}{c}\text { 1972: } \\
1-2011: 4\end{array}$ & $\begin{array}{l}\text { ARDL Model, Johnsen co-integration, and VECM Granger } \\
\text { causality }\end{array}$ & Feedback hypothesis \\
\hline Apergis and Payne (2010) & Eurasia & 1992-2007 & $\begin{array}{l}\text { Pedroni co-integration, FMOLS, and VECM Granger } \\
\text { causality }\end{array}$ & Feedback hypothesis \\
\hline Lee and Jung (2018) & South Korea & 1990-2012 & ARDL Model and VECM Granger causality & Conservation hypothesis \\
\hline Ohler and Fetters (2014) & 20 OECD states & 1990-2008 & $\begin{array}{l}\text { Pedroni co-integration, FMOLS, DOLS, and VECM } \\
\text { Granger causality }\end{array}$ & Feedback hypothesis \\
\hline Azam et al. (2021) & $\mathrm{CO}_{2}$ emitter countries & $2000-2016$ & Regression analysis & $\begin{array}{l}\text { REN contributes to economic } \\
\text { growth }\end{array}$ \\
\hline Azam et al. (2020) & Developing countries & 1990-2017 & ARDL and causality test & Feedback hypothesis \\
\hline Niu et al. (2013) & 50 income countries & 1990-2009 & Panel co-integration and causality test & Feedback hypothesis \\
\hline Ouedraogo (2013) & $\begin{array}{l}15 \text { developing } \\
\text { countries }\end{array}$ & 1988-2008 & Panel co-integration and error correction term & Conservation hypothesis \\
\hline Sasmaz et al. (2020) & 28 OECD & 1990-2017 & Edgerton panel co-integration and causality test & Feedback hypothesis \\
\hline Yumashev et al. (2020) & OECD & 2006-2017 & $3 S L S$ & REN contributes to HDI \\
\hline Abid et al. (2020) & Pakistan & 1990-2017 & Regression and causality analysis & Neutrality hypothesis \\
\hline
\end{tabular}

Note: OECD, Organization for EConomic Co-Operation and Development, 3SLS, three-stage least squares; FMOLS: fully modified ordinary least squares; DOLS: dynamic ordinary least squares; VECM: vector error correction model; ARDL: auto-regressive distributed lag model.

Alper and Oguz (2016); Sebri and Ben-Salha (2014) premeditated the link between sustainable power usage and economic expansion in the EU countries and confirmed the neutrality hypothesis. In most countries along the BRI, the rise in the renewable energy scale is the main driving force responsible for encouraging $\mathrm{CO}_{2}$ emissions, while the carbon intensity of renewable energy is the main factor restraining $\mathrm{CO}_{2}$ emissions. (Wang et al., 2021; Chang et al., 2015; Lin and Moubarak, 2014) found bidirectional causality amid renewable energy use and economic escalation. Unidirectional correlation occurs between renewable energy use to GDP in developing nations (Saidi and Mbarek 2016).

Another study by Dong et al. (2020) found that renewable energy consumption reduces $\mathrm{CO}_{2}$ emissions, but the effect is minor; the mitigating benefit may be masked by increased nonrenewable energy consumption and higher economic growth. The link between renewable energy consumption and growth has been extensively studied (Dogan, 2016; Inglesi-Lotz, 2016; Kahia and Charfeddine, 2016; Koçak and Şarkgüneşi 2017; Rafindadi and Ozturk, 2017), but in addition to the impact of energy on economic growth, it also has an impact on the human development index. The influence of human development on economic growth has been analyzed by many authors in the past decades. Most of the evidence in this area confirms a positive effect on economic growth. Some empirical inquiries on the causal correlation between renewable energy growth and renewable energy HDI are summarized in Table $\mathbf{1}$.

For instance, Ranis (2004) examined the linkage between HDI and economic expansion. According to the findings of the inquiry, human development has a significant impact on economic growth; as a result, it improves human development. Similarly, gross domestic product (GDP) and other HDI, longevity, and instructional accomplishment elements improve a country's financial development at various stages (Hou et al., 2015; Shah, 2016). From 1975 to 2008, an error correction model is used to examine the relationship between economic growth and the human development index in Nigeria (Abraham and Ahmed,
2011). The findings suggest that economic augmentation has a negative correlation with the human development index in the short run, but it is significant for the long-run relationship. Similarly, other studies (Khodabakhshi, 2011; Costantini and Monni, 2005) found that the evolution of human development performs an imperative function to form a sustainable progress path for the case of India and 179 countries.

The world has been remade thanks to ICT in terms of scrimping and enhancing access to information and human capital, which authorize individuals via influencing their mental capacity, thinking power, and capacity to liaise with others (Summak et al., 2010; Coelho et al., 2015). However, in particular, people who live in rural regions that have low income frequently face hindrance in accessing educational prospects, where ICT endorses practical and useful ways to alleviate the trouble of accessing education by home-based education and e-learning. Therefore, ICT has the potential effect on development to eradicate impediments in people's lives and to improve their living standards through access to education and health-related information (Palvia et al., 2015; Migliaccio 2016). Previous studies have widely reviewed the association between ICT and economic growth and conclude with positive or negative linkage. For example, ICT's contribution to GDP was compared from 1980 to 2000 in nine OECD countries. According to the findings, ICT assets contributed significantly to GDP in industrial nations (Colecchia and Schreyer, 2002). The carbon emission intensity of ICT investments adds to a large increase in carbon emissions, whereas the structure and efficiency of ICT investments always limit carbon emission growth (Wang et al., 2021). Similarly, other studies (Papaioannou and Dimelis, 2007; Katz, 2012; Zafar n.d.) revealed an affirmative and momentous influence on economic enlargement (Toader et al., 2018). By employing panel data estimation practices, researchers looked at the influence of ICT infrastructure on economic development in European Union (EU) nations from 2000 to 2017. 
The ICT industry might be used to certify the environmental quality in industrial operations, electrical grids, and transportation networks (Añón et al., 2017).

The empirical findings imply an affirmative and vigorous effect of using ICT infrastructure on economic augmentation, although the amount of the benefit varies depending on the type of technology studied. Similarly (Chimbo, 2020), ICT increased economic growth through its energy efficiency effect in Africa by using the GMM model from 2001 to 2015. Since ICT and human development have remained important topics in recent years, Gupta et al. (2019) evaluated how evolution in ICT could stimulate human capital advancement for the South Asian region over the period of 2000 to 2016 by using the panel fixed effects model. The results revealed a strong positive connection of internet access, technological readiness, and mobile use with the human development index. Khan et al. (2019) analyzed the association between ICT, economic growth, and the HDI for the period from 1990 to 2014 by using ARDL and VECM approaches in Pakistan. The findings suggest that ICT boosts the human development index and economic growth and has a constructive and significant influence on human development.

Little research has been carried out on linkage among links between the use of renewable energy and the human development index. For instance, using the 2SLS technique, Wang et al. (2018) scrutinized the association between renewable energy usage, economic growth, and human development index in Pakistan from 1990 to 2014. The empirical findings suggest that renewable energy does not contribute to the human development process in Pakistan. Energy use and HDI are strongly interrelated, and enough energy resources ensure mounting economic and human development in South Asia economies (Salam et al., 2020). Renewable energy has a negligible impact on HDI in high-income group countries (Amer, 2020).

In conclusion, ICT, renewable energy consumption, economic growth, and human development index have not been analyzed yet. The correlation between renewable energy, non-renewable energy, and economic growth is mostly disregarded but not lectured effectively. Human activities are responsible for a substantial amount of energy usage around the planet. According to the research, renewable energy is a vital component to augment economic growth that can help to reduce poverty and improve the human development index. Furthermore, scarce inquiries scrutinize the affiliation between renewable energy consumption and human development. Moreover, ICT has an enormous prospective for boosting GDP and enhancing HDI. Nevertheless, the present inquiry aims to close this gap on the potential of energy economy and environment liaison in the setting of selected developing states.

\section{EMPIRICAL METHODOLOGY AND THEORETICAL FRAMEWORK}

\subsection{Theoretical Framework}

Before going to the panel data econometric analysis, we need to construct the theoretical framework of our study that will assist us in deciding upon the model indicators. The developing countries referred to in this study are characterized by high economic growth, and this upward trend in economic growth is strongly related to the burning of fossil fuels, which results in an increase in $\mathrm{CO}_{2}$ emissions in these selected economies (Zafar et al., 2019). However, this type of traditional energy is not only harmful to the environment but also to the nation's long-lasting growth.

To tackle this kind of issue, a clean generation system comes to mind, which largely focuses on the use of renewable energy. This type of clean energy can be produced from a variety of sources, for example, tidal, wind, solar, and geothermal, and these are indispensable for the sustainable environment and economic growth. Now, putting the renewable energy-producing process in place necessitates a significant investment, which may impede economic development.

Saying this, remittances provide a potential impetus for national investment while also ensuring reliable and clean energy. For developing countries, remittance inflows have proven to be an economically indispensable source of cash. Moreover, the role of ICT is imperative in providing technological facilities for sustainable development. In a nutshell, ICT development not only improves economic growth but also has a substantial impact on human well-being, increases energy efficiency, and promotes environmental quality. In addition, there is a direct linkage between clean energy service, modern health and education facilities, sustainable growth, and environment as well as ICT. The lack of any indicator services leads to poor health facilities and fewer opportunities for education and development.

\subsection{Data Descriptions}

Annual data were collected from 1990 to 2017 in this current study by incorporating variables such as information and communication technologies (medium and high-tech exports), renewable energy (MTOE), economic growth (constant US\$), human development index (HDI), $\mathrm{CO}_{2}$ emissions (kt), and remittances (current US\$). The data for HDI and RE were extracted from the study by Cammack (2017) and the British Petroleum (BP) statistical Review of World Energy (Petroleum, 2019). The data for ICT, $\mathrm{CO}_{2}$ emissions, economic growth, and remittances were mined from the World Development Indicators (Bank, 2018). To lessen non-normality and heteroscedasticity, all these variables were transferred into a natural logarithm.

Regarding the list of developing countries in this study, it includes Azerbaijan, Belarus, Bangladesh, China, India, Indonesia, Iran, Iraq, Kazakhstan, Malaysia, Pakistan, Philippines, Russia, Sri Lanka, Ukraine, Vietnam, Algeria, Egypt, Morocco, South Africa, Argentina, Brazil, Chile, Colombia, Ecuador, Peru, Greece, Poland, Romania, and Turkey.

\subsection{Estimation Strategy}

The panel vector autoregressive (PVAR) model proposed by Love and Zicchino is employed in this study, which permitted us to account for overlooked entity heterogeneity for inclusive series 
and the presence of stationary endogenous variables. There are several econometric benefits within the PVAR model that make it a more appropriate method to examine macroeconomic dynamics. First, PVAR is useful in analyzing the transmission of shocks that can happen within a unit and time. Second, PVAR is based on existing series motion rather than a scrupulous notion of macroeconomy, which, if not approved, can be warping (Kireyev, 2000). Third, this model does not make dissimilarity among dependent and independent variables, and whole factors are treated as endogenous to one another. In addition, it provides a procedure of dependent and independent variables' jolts that are emphatically the most imperative sources of macroeconomic dynamics for small open states. Finally, the PVAR technique may also be employed to examine the significance of interdependencies and test whether the feedback is generalized (Canova and Ciccarelli, 2013). The specification of the PVAR model used in the empirical analysis is given in Eq. 1:

$$
Y_{i t}=\mu_{i t}+\Gamma(L) Y_{i t}+\varepsilon_{i t},
$$

where $Y_{i t}$ symbolizes the vector of stationary series in this study, $\mu_{i t}$ is the vector of deterministic fixed effects, $\Gamma$ (L) denotes a matrix polynomial in lag order with $\Gamma(\mathrm{L})=\Gamma_{1} \mathrm{~L}^{1}+\Gamma_{2} \mathrm{~L}^{2}+\ldots+\Gamma_{\mathrm{p}} \mathrm{L}^{\mathrm{p}}$, and $\varepsilon_{\text {it }}$ represent the random error term. The above matrix form of the PVAR model with the algorithm may also be revised in six equations, Eqs 2-7, as follows:

$$
\begin{aligned}
\Delta L H D I_{i t}= & \varphi_{1 j}+\sum_{k=1}^{m} a_{1 k} \Delta L H D I_{i t-k}+\sum_{k=1}^{m} b_{1 k} \Delta L R E_{i t-k} \\
& +\sum_{k=1}^{m} c_{1 k} \Delta L G D P_{i t-k}+\sum_{k=1}^{m} d_{1 k} \Delta L I C T_{i t-k} \\
& +\sum_{k=1}^{m} e_{1 k} \Delta L R E M_{i t-k}+\sum_{k=1}^{m} f_{1 k} \Delta L C O_{2 i t-k}+\varepsilon_{1 i t},
\end{aligned}
$$$$
\Delta L R E_{i t}=\varphi_{2 j}+\sum_{k=1}^{m} a_{2 k} \Delta L H D I_{i t-k}+\sum_{k=1}^{m} b_{2 k} \Delta L R E_{i t-k}
$$$$
+\sum_{k=1}^{m} c_{2 k} \Delta L G D P_{i t-k}+\sum_{k=1}^{m} d_{2 k} \Delta L I C T_{i t-k}
$$$$
+\sum_{k=1}^{m} e_{2 k} \Delta L R E M_{i t-k}+\sum_{k=1}^{m} f_{2 k} \Delta L C O_{2 i t-k} \varepsilon_{2 i t} \text {, }
$$$$
\Delta L G D P_{i t}=\varphi_{3 j}+\sum_{k=1}^{m} a_{3 k} \Delta L H D I_{i t-k}+\sum_{k=1}^{m} b_{3 k} \Delta L R E_{i t-k}
$$$$
+\sum_{k=1}^{m} c_{3 k} \Delta L G D P_{i t-k}+\sum_{k=1}^{m} d_{31 k} \Delta L I C T_{i t-k}
$$$$
+\sum_{k=1}^{m} e_{3 k} \Delta L R A M_{i t-k}+\sum_{k=1}^{m} f_{3 k} \Delta L C O_{2 i t-k}+\varepsilon_{3 i t} \text {, }
$$$$
\begin{aligned}
\Delta \operatorname{LICT}_{i t}= & \varphi_{4 j}+\sum_{k=1}^{m} a_{41 k} \Delta \mathrm{LHDI}_{i t-k}+\sum_{k=1}^{m} b_{4 k} \Delta \mathrm{LRE}_{i t-k} \\
& +\sum_{k=1}^{m} c_{4 k} \Delta \mathrm{LGDP}_{i t-k}+\sum_{k=1}^{m} d_{4 k} \Delta \mathrm{LICT}_{i t-k} \\
& +\sum_{k=1}^{m} e_{4 k} \Delta \mathrm{LREM}_{i t-k}+\sum_{k=1}^{m} f_{4 k} \Delta \mathrm{LCO}_{2 i t-k}+\varepsilon_{4 i t},
\end{aligned}
$$$$
\Delta L R A M_{i t}=\varphi_{5 j}+\sum_{k=1}^{m} a_{5 k} \Delta L H D I_{i t-k}+\sum_{k=1}^{m} b_{5 k} \Delta L R E_{i t-k}
$$$$
+\sum_{k=1}^{m} c_{51 k} \Delta L G D P_{i t-k}+\sum_{k=1}^{m} d_{5 k} \Delta L I C T_{i t-k}
$$$$
+\sum_{k=1}^{m} e_{5 k} \Delta L R E M_{i t-k}+\sum_{k=1}^{m} f_{51 k} \Delta L C O_{2 i t-k}+\varepsilon_{5 i t} \text {, }
$$

$$
\begin{aligned}
\Delta \mathrm{LCO}_{2 i t}= & \varphi_{6 j}+\sum_{k=1}^{m} a_{6 k} \Delta L \operatorname{HDI}_{i t-k}+\sum_{k=1}^{m} b_{6 k} \Delta L R E_{i t-k} \\
& +\sum_{k=1}^{m} c_{6 k} \Delta L G D \mathrm{P}_{i t-k}+\sum_{k=1}^{m} d_{6 k} \Delta L I C \mathrm{~T}_{i t-k} \\
& +\sum_{k=1}^{m} e_{6 k} \Delta L R E \mathrm{LM}_{i t-k}+\sum_{k=1}^{m} f_{6 k} \Delta L C \mathrm{CO}_{2 i t-k}+\varepsilon_{6 i t} .
\end{aligned}
$$

ICT represents information and communication technology; REM indicates the remittances, and $\mathrm{CO}_{2}$ is the carbon dioxide emission. The study used the Schwarz information (SIC) criterion to ascertain the best autoregressive lag length in the estimation process, $K \in(1 \ldots, p)$. The PVAR approach agrees to an enclosure of fixed effects in regions, which is nominated by 8)Pited capital formattion act $\varphi_{j}$, and accounts for all constant time factors that are not seen at the state level. Subscripts $i$ and $t$ represent the country and time, respectively. The theoretical framework of the VAR model is shown in Figure 1.

\section{EMPIRICAL RESULTS AND DISCUSSION}

The VAR model includes several steps. Before analysis, the first step is to analyze the detailed descriptive statistics. However, a comprehensive summary of the variables is provided in Appendix Table 2 with mean, variation (standard deviation), and bounds (minimum and maximum). Next, it is necessary to check the integration order of the studied variables. Thus, the primary goal of using a unit root test is to determine whether data contain a unit root. This study used three-unit root tests (Maddala and $\mathrm{Wu}$, 1999; Im et al., 2003; Levin et al., 2002) to analyze the stationarity of the variables.

The results of the unit root tests are illustrated in Table 3, including (Maddala and Wu, 1999; Im et al., 2003; Levin et al., 2002) variables that display that variables comprise a unit root at their levels, denoting that the variables are not stationary. All the coefficients of the variables' first difference are significant at the $1 \%$ level, indicating that all variables are stationary at their first difference. Choosing the lag order is the next stage. This stage aims to find the VAR model's optimal lag order, which is based on the following selection criteria: LR-sequential modified LR test statistics, Hannan-Quinn information criterion, and SIC-Schwarz information criterion. This process is required because if the lag length is chosen incorrectly, the results will be skewed (Hdom and Fuinhas, 2020). Table 4 shows that the result of the appropriate lag length is 2 .

Next, the outcomes of the panel vector autoregressive model using lag 2 with the GMM-style option are reported in Table 5. First, the HDI equation indicates that only three coefficients are statistically significant at the conventional level of significance. More particularly, findings indicate that the first lag length of HDI is positively interrelated with its recent stage. The predictable coefficient of HDI is equal to $0.139 \%$, and it is significant at the $1 \%$ level. Furthermore, the coefficient of usage of renewable energy positively resolves the current level of $\mathrm{HDI}$ at a $1 \%$ significance level, which specifies that rising renewable energy use will augment the level of HDI. The results 


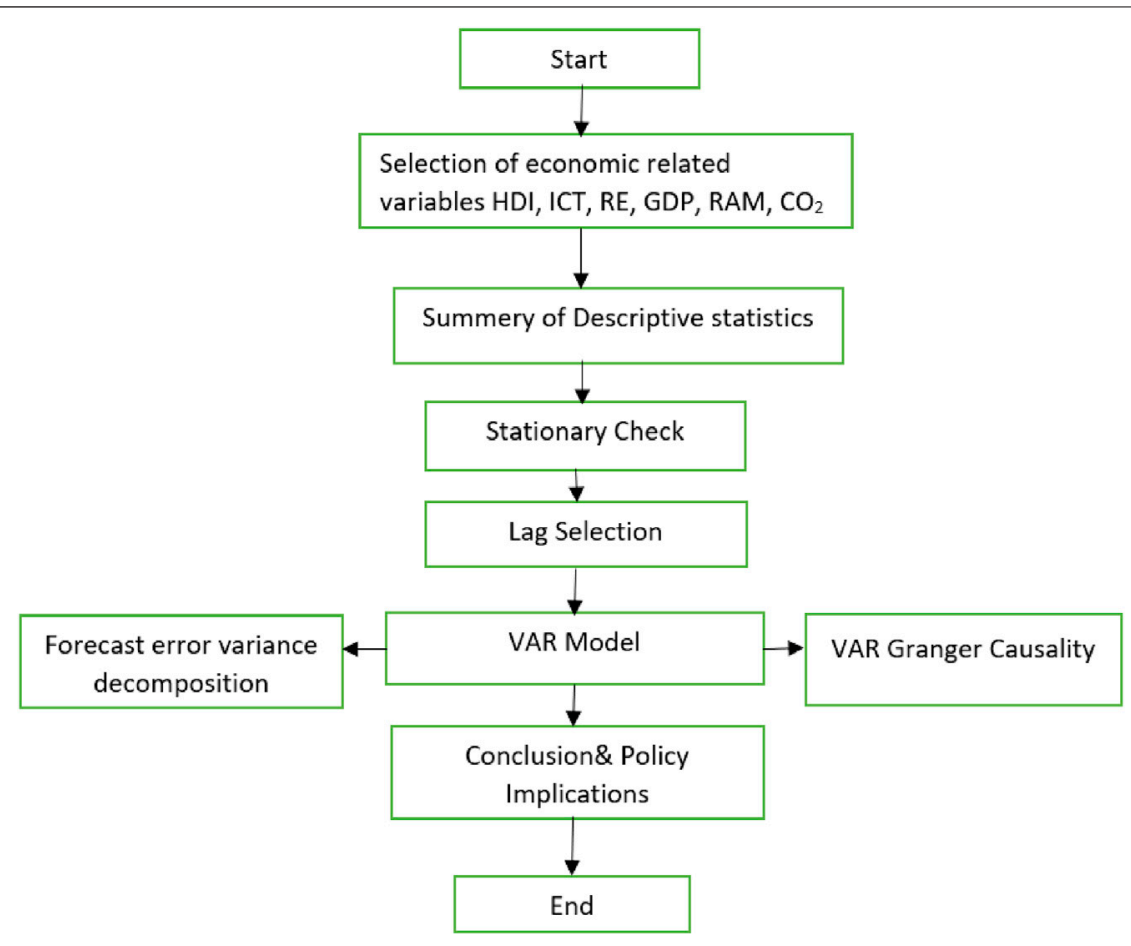

FIGURE 1 | Theoretical Model of the estimation strategy.

TABLE 2 | Descriptive Statistics of the variables.

\begin{tabular}{|c|c|c|c|c|c|c|}
\hline Variable & HDI & RE & GDP & ICT & REM & $\mathrm{CO}_{2}$ \\
\hline Median & -0.384193 & 1.995378 & 8.321284 & 3.348022 & 21.12906 & 11.59213 \\
\hline Mini & -0.931404 & -5.521461 & 2.825596 & -3.283799 & 0.296394 & 3.077312 \\
\hline Std.Dev & 0.316075 & 2.286571 & 1.141358 & 0.982249 & 3.215571 & 1.882120 \\
\hline
\end{tabular}

are similar to the findings of Abid et al. (2020); Sasmaz et al. (2020) but dissimilar to the study of Wang et al. (2018), who argued that renewable energy does not contribute to the situation of the human development index. As expected, the coefficient value of GDP is an optimistic and momentous effect on the human development index at a $1 \%$ level of significance, which shows that these countries need to provide more goods and services to improve the living standards of each country. Additionally, a surge in GDP lessens the unemployment rate and raises income, which will endorse human development. People favor devoting after-tax capital to education, food, and the health sector; these factors directly donate to human development (Engo, 2018). For any economy, human development is a critical predictor of economic progress. Greater levels of education, better health, and more income, all of which translate into a higher standard of living and more possibilities, boost the working force's intellectual aptitude and productivity. The coefficient of ICT is positively determined by the HDI at the $1 \%$ significance level, which specifies rising in technological innovation, and will help to augment the level of HDI because ICT plays an important part in the development course. This conclusion conforms to the studies by Khan et al. (2019); Gupta et al. (2019).

Second, the renewable energy equation findings specify that just two indicators have a vital influence on RE. HDI and RE coefficients are positive and significant at a $1 \%$ level, respectively. The results are in line with the study of Yahya and Rafiq (2020). This means that renewable energy improves the HDI in developing economies by economic development and leads toward higher human development levels. Without accessing and ensuring a clean, reliable, and efficient energy, it would not be possible to attain the social and economic development in developing nations. Third, in terms of the economic growth equation, GDP values positively and significantly impact the current value of GDP at $1 \%$ as expected; the outcomes display that these three coefficients are significant at the $1 \%$ significance level, which is reflected. Furthermore, as projected by the coefficient of remittances, we discovered that the value has a 
TABLE 3 | Panel unit root test results.

\begin{tabular}{llll}
\hline Method & Variables & Level & First difference \\
\hline ADF & & & \\
& LHDI & 74.279 & $240.639^{\mathrm{a}}$ \\
& LRE & 54.345 & $345.829^{\mathrm{a}}$ \\
& LGDP & 34.634 & $269.378^{\mathrm{a}}$ \\
& LICT & 60.925 & $184.121^{\mathrm{a}}$ \\
& LREM & 72.104 & $268.453^{\mathrm{a}}$ \\
& LCO 2 & 63.061 & $365.799^{\mathrm{a}}$ \\
IPS & & & \\
& LHDI & 0.1670 & $-10.300^{\mathrm{a}}$ \\
& LRE & 2.263 & $-15.771^{\mathrm{a}}$ \\
& LGDP & 5.295 & $-12.719^{\mathrm{a}}$ \\
& LICT & -0.890 & $-13.452^{\mathrm{a}}$ \\
& LREM & -0.417 & $-20.628^{\mathrm{a}}$ \\
LLC & LCO 2 & 1.722 & \\
& LHDI & & \\
& LRE & -0.268 & $-7.832^{\mathrm{a}}$ \\
& LGDP & 2.843 & $-12.805^{\mathrm{a}}$ \\
& LICT & -0.302 & $-11.836^{\mathrm{a}}$ \\
& LREM & -1.155 & $-22.083^{\mathrm{a}}$ \\
& LCO 2 & -0.805 & $-2.435^{\mathrm{a}}$ \\
\hline
\end{tabular}

Note: ${ }^{a}$ implies significance level at $1 \%$. $\mathrm{HDI}, \mathrm{GDP}, \mathrm{RE}, \mathrm{ICT}, \mathrm{REM}$, and $\mathrm{CO}_{2}$ represent the human development index, gross domestic product, renewable energy, information and communication technology, remittances, and carbon dioxide emission.

significant positive effect on remittances. The positive influence of GDP on remittances indicates that for every 1 unit increase in GDP, the remittances will increase by a $5 \%$ level. This means that developing countries need to improve their development levels by investing in physical and human capital and also contributing in remittances to ensure the efficient and reliable transfers and reducing the cost of transfers by increasing their political stability. Conclusively, environmental deprivation, which is signified by $\mathrm{CO}_{2}$ emanations, has a positive and significant influence at a $1 \%$ level of significance on the current GDP level. These findings conform with those of Xie et al. (2018); Charfeddine and Kahia (2019).

Fourth, only $\mathrm{CO}_{2}$ emissions have an adverse influence at a $1 \%$ level of significance on ICT in the equation related to the ICT variable. This finding shows that ICT significantly decreases $\mathrm{CO}_{2}$ emissions, and it may be regarded as one of the spillover impacts of spending on renewable energy sources. Thus, there is a need to explore and induce the use of cleaner energy sources. Another contribution to mitigate the environment is to encourage the latest ICT technologies that are less polluting and investing in research and development (R\&D) to provide opportunities to import new innovations. Fifth, two coefficients in the remittance equation are positive and significant at 5 and $1 \%$ levels. The finding indicates that coefficients of HDI and remittance variables are strongly related at 10 and $1 \%$ levels of significance, respectively. The significant and positive coefficient means that the increase in remittances will augment the human development index, such as education, the health sector, and the living standard in developing countries. Finally, in the $\mathrm{CO}_{2}$ emission equation, the outcomes embody that only ICT improves environmental quality through the latest technology and innovations.

Next, to conclude the alteration of sources in the variance decomposition of variables in the PVAR model, variance decomposition exploration is applied in Table 6. This method acquired from the moving averages section of the PVAR model articulates the source of the shocks that happen in the variables themselves and other variables as a percentage. The findings of the variance decomposition show that HDI explains approximately $0.371,0.184,1.224,0.221$, and $4.25 \%$ of the variations in GDP, renewable energy consumption, ICT, REM, and $\mathrm{CO}_{2}$ emission, respectively. In addition, usage of renewable energy explicates around $0.101 \%$ of variations in HDI, $2.698 \%$ of the vicissitudes in $\mathrm{CO}_{2}$ discharge, and $0.258 \%$ of disparity in economic enlargement; economic growth explains approximately

\begin{tabular}{|c|c|c|c|c|c|c|}
\hline Lag & LogL & LR & FPE & AIC & sc & $H Q$ \\
\hline 0 & $-6,688.408$ & NA & 9.630915 & 19.29224 & 19.33151 & 1930743 \\
\hline 2 & -1840.200 & 365.6038 & $1.01 \mathrm{e}-05^{\mathrm{sc}}$ & $5.527954 \mathrm{sc}$ & $6.038491^{\mathrm{sc}}$ & $5.725385^{\mathrm{sc}}$ \\
\hline 3 & -1806.359 & $65.82852 \mathrm{sc}$ & $1.02 \mathrm{e}-05$ & 5.534177 & 6.280346 & 5.822730 \\
\hline
\end{tabular}

\begin{tabular}{|c|c|c|c|c|c|c|}
\hline Response to & LHDI & LRE & LGDP & LICT & LREM & $\mathrm{LCO}_{2}$ \\
\hline LRE & $0.034802^{a}$ & $0.962296^{a}$ & 0.000812 & 0.001495 & 0.0006300 & -0.009355 \\
\hline LGDP & $0.059813^{a}$ & 0.004706 & $0.986979^{a}$ & 0.010608 & -0.036821 & 0.071178 \\
\hline LICT & $0.034802^{a}$ & 0.001434 & 0.002642 & 0.919910 & 0.006583 & $-0.012288^{b}$ \\
\hline
\end{tabular}

Note: ${ }^{a, b, c}$ denote significance level at 1,5 , and $10 \%$, respectively. 
TABLE 6 | Variance decomposition of the PVAR (\%).

\begin{tabular}{lcccccc}
\hline Variables & LHDI & LRE & LGDP & LICT & LREM & $\mathbf{L C O}_{\mathbf{2}}$ \\
\hline LHDI & 93.746 & 0.371 & 0.184 & 1.224 & 0.221 & 4.252 \\
LRE & 0.101 & 84.49 & 0.258 & 0.054 & 0.093 & 2.698 \\
LGDP & 0.480 & 0.216 & 67.733 & 1.153 & 0.287 & 30.128 \\
LICT & 0.064 & 0.180 & 0.236 & 93.190 & 0.020 & 6.307 \\
LRAM & 0.137 & 0.163 & 0.034 & 0.179 & 90.442 & 9.089 \\
LCO $_{2}$ & 0.098 & 0.087 & 0.351 & 0.914 & 1.441 & 97.193 \\
\hline
\end{tabular}

Note: $\%$ of the variation in the column variable (10 periods ahead) explicate by the row variable.

$0.480 \%$ of the changes in HDI and $0.216 \%$ of oscillation in clean energy. ICT explains approximately $0.064 \%$ of amending in HDI and $6.307 \%$ of fluctuations in $\mathrm{CO}_{2}$ emission.

After PVAR estimation and variance decomposition analysis, we performed the Granger causality test (Granger, 1969) based on the Wald check. The null hypothesis is the absence of Granger causality. Table 7 represents the Granger causality test. The outcomes show that bidirectional causation is occurring between the use of renewable energy and HDI. In addition, there is unidirectional causality from economic expansion to human development index, from ICT to human development index, and from remittances to human development index and $\mathrm{CO}_{2}$ emission to HDI. However, there is a one-way antecedent from renewable energy usage to $\mathrm{CO}_{2}$ release and from economic enlargement to remittances and $\mathrm{CO}_{2}$ emissions. The causality associations between variables are represented in Figure 2.

These findings indicate that an increase in renewable energy may lead to an increase HDI in developing countries. However, improvement in the level of clean energy (health and education sectors) will add to the nations' economic augmentation. However, more investment in the clean energy sector is needed; developing countries must join forces to achieve levels of investment capable of meeting expectations. Furthermore, an increase in economic growth would lead to augment the level of HDI in developing regions. Economic growth makes this likely to accomplish a high level of human development, and in contrast, a rise in the level of human development results in increased prospects for economic growth. Moreover, ICT performs a significant part in the development process through ICTenabled technologies that will bring innovative changes in education, health services, and industrial purposes; in this way, the government may develop labor skill development and technical training organizations to more productivity for highincome gains, which will further lead to increased economic growth and human development index. When migrant workers send money home to their families in poor nations, it improves HDI. As a result, remittances have an important role in boosting economic activity by increasing aggregate spending and expanding access to critical social infrastructure such as health and education, all of which contribute to improved social wellbeing. Furthermore, to contest any environmental threat from excessive energy consumption, more renewable energy should be adopted to the energy mix. $\mathrm{CO}_{2}$ emissions influence the human development process in developing economies, and a low level of the human development index leads to environmental degradation. Therefore, clean energy is critical for improving environmental quality, which aids in the advancement of the human development index.

\section{CONCLUSION AND POLICY IMPLICATIONS}

This analysis examined correlation among ICT, human development index, renewable power usage, and economic development, incorporating remittances and $\mathrm{CO}_{2}$ emission in the context of developing nations by utilizing the PVAR practice that Love and Zicchino lately established for 1990-2017. We applied the Toda-Yamamoto-Granger casualty methodology to analyze the study's underlying variables.

The empirical results can be outlined in four essential points. First, we investigated that economic expansion has a large positive impact on the human development index, and an increase in GDP will accelerate human development. For sustainable economic growth, developing countries can direct more plans for better education facilities, health, and other social and economic sectors. Second, ICT and remittances stimulate the human development process. The significant results show that both ICT and the remittance sector play a decisive role in the development process. Third, the use of renewable energy has a positive and significant effect on HDI. Additionally, we found that ICT helps improve $\mathrm{CO}_{2}$ emissions. Finally, $\mathrm{CO}_{2}$ emissions and remittances have a noteworthy effect on economic expansion. Based on causality findings, we discovered that economic growth, remittances, and $\mathrm{CO}_{2}$ emission Granger cause to human development index. Thus, there is

TABLE 7 | Granger causality Wald test.

\begin{tabular}{|c|c|c|c|c|c|c|}
\hline \multirow[t]{2}{*}{ Independent variable } & \multicolumn{6}{|c|}{ Dependent variable } \\
\hline & LHDI & LRE & LGDP & LICT & LREM & $\mathrm{LCO}_{2}$ \\
\hline LHDI & - & $4.733^{\mathrm{b}}$ & 1.076 & $7.735^{\mathrm{a}}$ & 0.776 & 2.609 \\
\hline LGDP & $32.732^{\mathrm{a}}$ & 0.566 & - & 1.505 & $6.627^{b}$ & $6.403^{b}$ \\
\hline LICT & 0.238 & 0.036 & 0.529 & - & 0.037 & 1.464 \\
\hline LREM & $2.587^{\mathrm{c}}$ & 0.001 & 1.363 & 0.030 & - & 1.286 \\
\hline $\mathrm{LCO}_{2}$ & $0.720^{c}$ & 0.124 & 1.355 & 1.347 & $3.871^{b}$ & - \\
\hline
\end{tabular}

Note: ${ }^{a, b, c}$ denote significance levels at 1, 5, and 10\%, respectively. 


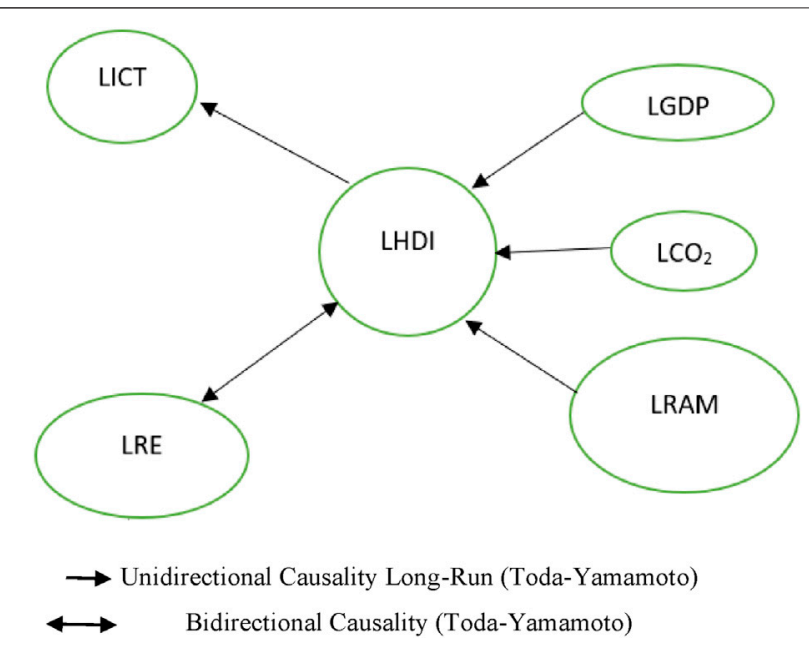

FIGURE 2 | Causality relationship. Unidirectional causality long-run (Toda-Yamamoto) and bidirectional causality (Toda-Yamamoto).

unidirectional causality from HDI to renewable energy and ICT, while renewable energy Granger causes $\mathrm{CO}_{2}$ emission.

However, the empirical findings suggest that policymakers and government officials should make ICT-related policies more effective in terms of economic growth to stimulate human development. Furthermore, it reinforces the ICT and R\&Drelated projects that support a better human development index and enhances the usage of renewable energy that is helpful to the construction of a clean environment. The efficient use of renewable energy is helpful to improve the quality of life of poor masses, economic empowerment, and consequently improve human development. However, renewable energy resources are imperative in achieving an efficient and reliable human development index for developing countries.

Furthermore, policymakers should empower people with ICT expertise to offer trained labor force to marketplace and prospects through education, health services that broaden people's horizons, and competencies to contribute to institutions responsible for providing social facilities and economic inducements for the development. Moreover, economic growth makes this likely to realize a high degree of human development, an enhancement in the level of human development results in rising prospects for economic growth.

The positive coefficient of GDP on $\mathrm{CO}_{2}$ emission suggests that with an increase in income, pollution levels start to increase due to inefficient energy use and consumption of more goods. Nevertheless, countries must enhance understanding by promotions and basic amendments at the state and global levels, which assist in raising the growth without accelerating the environmental contamination that would deliver environment-friendliness. Similarly, numerous nations adopted the latest environmental strategies and policies to slash environmental outward. Economic affluence results in larger energy consumption. Therefore, modification of green power revolutions and energy efficiency policies via ICT would be beneficial for economic and ecological sustainability. Furthermore, $\mathrm{CO}_{2}$ mitigation measures based on the "Paris agreement" are inadequate as continual decarburization operations are not fully acknowledged in numerous countries (Sun et al., 2020).

The outbreak of COVID-19 has severely affected episodic national and global economic growth and the energy industry at an unprecedented pace; the expected losses of GDP due to outbreak of the novel coronavirus was roughly $0.42 \%$ in the first quarter of the year (Azam et al., 2021), and still, this disease is underway in worldwide. The emergence of this pandemic is causing a huge impact on global socioeconomic factors such as higher unemployment, poverty rates, health insecurity, and loss of education, energy, and environmental pollution. However, due to the shutting down of the industries, e-commerce is highlighted, and businesses with more developed e-commerce infrastructures have shown more resilience to the economic shock caused by the epidemic situation. Furthermore, it is necessary to develop defensive epidemiological models to discover the occurrence of viruses, for example, COVID-19.

In addition, governments and policymakers need to take essential steps like healthcare services for better prevention of viruses for all citizens and suggested that more investment is needed in research and development programs to control this pandemic or other related similar crises for the sustainable energy sector and economic development in the future.

Since this study enables us to draw some preliminary conclusions on the human development index, ICT, and renewable energy-growth nexus, certain investigations still need to be looked further. First, this study is limited to emerging or developing economies; this leaves room for the future to research advanced countries. Second, the panel data research should be supplemented with individual economy time-series estimations. This gives us a better understanding of the idiosyncratic and draws a clear policy implication. Last, future studies can enhance the number of variables and different methodologies to explore the relationship further.

\section{DATA AVAILABILITY STATEMENT}

The original contributions presented in the study are included in the article/Supplementary Material, further inquiries can be directed to the corresponding author.

\section{AUTHOR CONTRIBUTIONS}

AA: conceptualization, methodology, software, data curation, writing-original draft, visualization, validation, and writing-reviewing and editing; MR: conceptualization, methodology, software, and writing-original draft, reviewing, and editing; MS: conceptualization, methodology, and writing-reviewing and editing; SS: conceptualization and funding acquisition; JY: conceptualization, methodology, and supervision. 


\section{REFERENCES}

Abid, N., Wu, J., Ahmad, F., Draz, M. U., Chandio, A. A., and Xu, H. (2020). Incorporating Environmental Pollution and Human Development in the Energy-Growth Nexus: A Novel Long Run Investigation for Pakistan. Ijerph 17, 5154. doi:10.3390/ijerph17145154

Abraham, T. W., and Ahmed, U. A. (2011). Economic Growth and Human Development Index in Nigeria : An Error Correction Model Approach. Nigeria: International Journal of Administration and Development Studies, University of Maiduguri.

Alper, A., and Oguz, O. (2016). The Role of Renewable Energy Consumption in Economic Growth: Evidence from Asymmetric Causality. Renew. Sustain. Energ. Rev. 60, 953-959. doi:10.1016/j.rser.2016.01.123

Amer, H. (2020). The Impact of Renewable Energy Consumption on the Human Development Index in Selected Countries: Panel Analysis (1990-2015). Int. J. Economy, Energ. Environ. 5, 47. doi:10.11648/j.ijeee.20200504.12

Añón Higón, D., Gholami, R., and Shirazi, F. (2017). ICT and Environmental Sustainability: A Global Perspective. Telematics Inform. 34, 85-95. doi:10.1016/ j.tele.2017.01.001

Apergis, N., and Payne, J. E. (2010). Renewable Energy Consumption and Growth in Eurasia. Energ. Econ. 32, 1392-1397. doi:10.1016/j.eneco.2010.06.001

Azam, A., Rafiq, M., Shafique, M., Zhang, H., and Yuan, J. (2020). Analyzing the Effect of Natural Gas, Nuclear Energy and Renewable Energy on GDP and Carbon Emissions: A Multi-Variate Panel Data Analysis. Energy 219, 119592. doi:10.1016/j.energy.2020.119592

Azam, A., Rafiq, M., Shafique, M., Ateeq, M., and Yuan, J. (2021a). Investigating the Impact of Renewable Electricity Consumption on Sustainable Economic Development: A Panel ARDL Approach. Int. J. Green Energ. 18, 1185-1192. doi:10.1080/15435075.2021.1897825

Azam, A., Rafiq, M., Shafique, M., and Yuan, J. (2021c). An Empirical Analysis of the Non-linear Effects of Natural Gas, Nuclear Energy, Renewable Energy and ICT-Trade in Leading CO2 Emitter Countries: Policy towards CO2 Mitigation and Economic Sustainability. J. Environ. Manage. 286, 112232. doi:10.1016/ j.jenvman.2021.112232

Azam, A., Rafiq, M., Shafique, M., and Yuan, J. (2021b). Renewable Electricity Generation and Economic Growth Nexus in Developing Countries: An ARDL Approach. Econ. Research-Ekonomska Istraživanja 34, 2423-2446. doi:10.1080/ 1331677X.2020.1865180

Azam, A., Rafiq, M., Shafique, M., Zhang, H., Ateeq, M., and Yuan, J. (2021d). Analyzing the Relationship between Economic Growth and Electricity Consumption from Renewable and Non-renewable Sources: Fresh Evidence from Newly Industrialized Countries. Sustainable Energ. Tech. Assessments 44, 100991. doi:10.1016/j.seta.2021.100991

Bank, World (2018). World Development Report 2019: The Changing Nature of Work.

Bhattacharya, M., Paramati, S. R., Ozturk, I., and Bhattacharya, S. (2016). The Effect of Renewable Energy Consumption on Economic Growth: Evidence from Top 38 Countries. Appl. Energ. 162, 733-741. doi:10.1016/ j.apenergy.2015.10.104

Cammack, P. (2017). The UNDP, the World Bank and Human Development through the World Market. Dev. Pol. Rev 35 (1), 3-21. doi:10.1111/ dpr. 12198

Canova, F., and Ciccarelli, M. (2013). Panel Vector Autoregressive Models: A Survey. Frankfurt a. M.: European Central Bank (ECB). doi:10.1108/s0731-9053(2013) 0000031006

Chang, T., Gupta, R., Inglesi-Lotz, R., Simo-Kengne, B., Smithers, D., and Amy, T. (2015). Renewable Energy and Growth: Evidence from Heterogeneous Panel of G7 Countries Using Granger Causality 52, 1405-1412.

Charfeddine, L., and Kahia, M. (2019). Impact of Renewable Energy Consumption and Financial Development on CO2 Emissions and Economic Growth in the MENA Region: A Panel Vector Autoregressive (PVAR) Analysis. Renew. Energ. 139, 198-213. doi:10.1016/j.renene.2019.01.010

Chimbo, B. (2020). Energy Consumption, Information and Communication Technology and Economic Growth in an African Context. Ijeep 10, 486-493. doi:10.32479/ijeep.8118

Coelho, T. R., Segatto, A. P., and Frega, J. R. (2015). Analysing ICT and Development from the Perspective of the Capabilities Approach: A Study in
South Brazil. The Electron. J. Inf. Syst. Developing Countries 67, 1-14. doi:10.1002/j.1681-4835.2015.tb00480.x

Colecchia, A., and Paul, S. (2002). ICT Investment and Economic Growth in the 1990s: Is the United States a Unique Case? A Comparative Study of Nine OECD Countries. Rev. Econ. Dyn. 5, 408-442. doi:10.1006/redy.2002.0170

Costantini, V., and Monni, S. (2005). Sustainable Human Development for European Countries. J. Hum. Develop. 6, 329-351. doi:10.1080/ 14649880500287654

Dogan, E. (2016). Analyzing the Linkage between Renewable and Non-renewable Energy Consumption and Economic Growth by Considering Structural Break in Time-Series Data. Renew. Energ. 99, 1126-1136. doi:10.1016/ j.renene.2016.07.078

Dong, K., Dong, X., and Jiang, Q. (2020). How Renewable Energy Consumption Lower Global CO 2 Emissions? Evidence from Countries with Different Income Levels. World Econ. 43 (6), 1665-1698. doi:10.1111/twec.12898

Engo, J. (2018). Decomposing the Decoupling of CO2 Emissions from Economic Growth in Cameroon. Environ. Sci. Pollut. Res. 25, 35451-35463. doi:10.1007/ s11356-018-3511-z

Granger, C. W. J. (1969). Investigating Causal Relations by Econometric Models and Cross-Spectral Methods. Econometrica 37, 424. doi:10.2307/1912791

Gupta, S., Jain, M., and Nagpal, A. (2019). An Empirical Investigation on Associated Linkage between Human Development and ICT: A South Asian Perspective. Germany: University Library of Munich.

Hdom, H. A. D., and Fuinhas, J. A. (2020). Energy Production and Trade Openness: Assessing Economic Growth, CO2 Emissions and the Applicability of the Cointegration Analysis. Energ. Strategy Rev. 30, 100488. doi:10.1016/j.esr.2020.100488

Hou, J., Walsh, P. P., and Zhang, J. (2015). The Dynamics of Human Development Index. Soc. Sci. J. 52, 331-347. doi:10.1016/j.soscij.2014.07.003

Im, K. S., Hashem Pesaran, M., and Shin, Y. (2003). Testing for Unit Roots in Heterogeneous Panels. J. Econom. 115, 53-74. doi:10.1016/S0304-4076(03) 00092-7

Inglesi-Lotz, R. (2016). The Impact of Renewable Energy Consumption to Economic Growth: A Panel Data Application. Energ. Econ. 53, 58-63. doi:10.1016/j.eneco.2015.01.003

Kahia, M., Ben Aïssa, M. S., and Charfeddine, L. (2016). Impact of Renewable and Non-renewable Energy Consumption on Economic Growth: New Evidence from the MENA Net Oil Exporting Countries (NOECs). Energy 116, 102-115. doi:10.1016/j.energy.2016.07.126

Katz, R. (2012). The Impact of Broadband on the Economy: Research to Date and Policy Issues. Columbia: Broadband Series.

Khan, N. H., Ju, Y., and Hassan, S. T. (2019). Investigating the Determinants of Human Development Index in Pakistan: An Empirical Analysis. Environ. Sci. Pollut. Res. 26, 19294-19304. doi:10.1007/s11356-019-05271-2

Khodabakhshi, A. (2011). Relationship between GDP and Human Development Indices in India. Int. J. Trade, Econ. Finance 2, 251-253. doi:10.7763/ ijtef.2011.v2.111

Kireyev, A. (2000). Comparative Macroeconomic Dynamics in the Arab World: A Panel Var Approach. IMF Working Pap. 00, 1. doi:10.5089/9781451847505.001

Kirikkaleli, D., and Adebayo, T. S. (2021b). Do Renewable Energy Consumption and Financial Development Matter for Environmental Sustainability? New Global Evidence. Sustain. Develop. 29 (4), 583-594. doi:10.1002/sd.2159

Kirikkaleli, D., and Adebayo, T. S. (2021a). Do Public-Private Partnerships in Energy and Renewable Energy Consumption Matter for Consumption-Based Carbon Dioxide Emissions in India. Environ. Sci. Pollut. Res. 28, 1-14. doi:10.1007/s11356-021-12692-5

Koçak, E., and Şarkgüneşi, A. (2017). The Renewable Energy and Economic Growth Nexus in Black Sea and Balkan Countries. Energy Policy 100, 51-57. doi:10.1016/j.enpol.2016.10.007

Lee, S.-H., and Jung, Y. (2018). Causal Dynamics between Renewable Energy Consumption and Economic Growth in South Korea: Empirical Analysis and Policy Implications. Energ. Environ. 29, 1298-1315. doi:10.1177/ $0958305 X 18776546$

Levin, A., Lin, C. F., and Chu, C. S. J. (2002). Unit Root Tests in Panel Data: Asymptotic and Finite-Sample Properties. J. Econom. 108:1-24. doi:10.1016/ S0304-4076(01)00098-7

Liddle, B. (2018). Consumption-Based Accounting and the Trade-Carbon Emissions Nexus. Energ. Econ. 69, 71-78. doi:10.1016/j.eneco.2017.11.004 
Lin, B., and Mohamed, M. (2014). Renewable Energy Consumption - Economic Growth Nexus for China. Renew. Sustain. Energ. Rev. 40, 111-117. doi:10.1016/ j.rser.2014.07.128

Maddala, G. S., and Wu., S. (1999). A Comparative Study of Unit Root Tests with Panel Data and a New Simple Test. Oxford Bull. Econ. Stat. 61, 631-652. doi:10.1111/1468-0084.0610s1631

Migliaccio, G. (2016). ICT for Disability Management in the Net Economy. Int. J. Globalisation Small Business 8, 51. doi:10.1504/IJGSB.2016.076452

Niu, S., Jia, Y., Wang, W., He, R., Hu, L., and Liu, Y. (2013). Electricity Consumption and Human Development Level: A Comparative Analysis Based on Panel Data for 50 Countries. Int. J. Electr. Power Energ. Syst. 53, 338-347. doi:10.1016/j.ijepes.2013.05.024

OECD (2010). ICTs for Development: Improving Policy Coherence. Français: OECD.

Ohler, A., and Fetters, I. (2014). The Causal Relationship between Renewable Electricity Generation and GDP Growth: A Study of Energy Sources. Energ. Econ. 43, 125-139. doi:10.1016/j.eneco.2014.02.009

Ouedraogo, N. S. (2013). Energy Consumption and Human Development: Evidence from a Panel Cointegration and Error Correction Model. Energy 63, 28-41. doi:10.1016/j.energy.2013.09.067

Palvia, P., Baqir, N., and Nemati, H. (2015). ICT Policies in Developing Countries: AN Evaluation with the Extended Design-Actuality Gaps Framework. Electron. J. Inf. Syst. Developing Countries 71, 1-34. doi:10.1002/j.16814835.2015.tb00510.x

Papaioannou, S. K., and Dimelis, S. P. (2007). Information Technology as a Factor of Economic Development: Evidence from Developed and Developing Countries. Econ. Innovation New Tech. 16, 179-194. doi:10.1080/ 10438590600661889

Petroleum, B. (2019). BP Statistical Review of World Energy Report. London, UK: BP.

Rafindadi, A. A., and Ozturk, I. (2017). Impacts of Renewable Energy Consumption on the German Economic Growth: Evidence from Combined Cointegration Test. Renew. Sustain. Energ. Rev. 75, 1130-1141. doi:10.1016/ j.rser.2016.11.093

Rahman, M. M., Velayutham, E., and Velayutham, E. (2020). Renewable and Nonrenewable Energy Consumption-Economic Growth Nexus: New Evidence from South Asia. Renew. Energ. 147, 399-408. doi:10.1016/j.renene.2019.09.007

Ranis, G. (2004). Human Development and Economic Growth. Yale University. Available at SSRN 551662.

Saidi, K., and Ben Mbarek, M. (2016). Nuclear Energy, Renewable Energy, CO 2 Emissions, and Economic Growth for Nine Developed Countries: Evidence from Panel Granger Causality Tests. Prog. Nucl. Energ. 88, 364-374. doi:10.1016/j.pnucene.2016.01.018

Salam, R. A., Amber, K. P., Ratyal, N. I., Alam, M., Akram, N., Gómez Muñoz, C. Q., et al. (2020). An Overview on Energy and Development of Energy Integration in Major South Asian Countries: The Building Sector. Energies 13, 5776. doi:10.3390/en13215776

Sasmaz, M. U., Sakar, E., Yayla, Y. E., and Akkucuk, U. (2020). The Relationship between Renewable Energy and Human Development in OECD Countries: A Panel Data Analysis. Sustainability 12, 7450. doi:10.3390/SU12187450

Sebri, M., and Ben-Salha, O. (2014). On the Causal Dynamics between Economic Growth, Renewable Energy Consumption, CO2 Emissions and Trade Openness: Fresh Evidence from BRICS Countries. Renew. Sustain. Energ. Rev. 39, 14-23. doi:10.1016/j.rser.2014.07.033

Shah, S. (2016). Determinants of Human Development Index: A Cross-Country Empirical Analysis. Int. J. Econ. Manage. Stud. 3, 43-46. doi:10.14445/ 23939125/ijems-v3i5p106

Shahbaz, M., Lean, H. H., and Shabbir, M. S. (2012). Environmental Kuznets Curve Hypothesis in Pakistan: Cointegration and Granger Causality. Renew. Sustain. Energ. Rev. 16, 2947-2953. doi:10.1016/j.rser.2012.02.015

Shahbaz, M., and Sinha, A. (2019). Environmental Kuznets Curve for CO2 Emissions: A Literature Survey. J. Econ. Stud. 46, 106-168. doi:10.1108/jes09-2017-0249

Solarin, S. A., Shahbaz, M., Khan, H. N., and Razali, R. B. (2019). ICT, Financial Development, Economic Growth and Electricity Consumption: New Evidence from Malaysia. Glob. Business Rev. 22, 941-962. doi:10.1177/ 0972150918816899
Summak, M. S., Bağlibel, M., and Samancioǧlu, M. (2010). Technology Readiness of Primary School Teachers: A Case Study in Turkey. Proced. - Soc. Behav. Sci. 2, 2671-2675. doi:10.1016/j.sbspro.2010.03.393

Sun, H., Samuel, C. A., Kofi Amissah, J. C., Taghizadeh-Hesary, F., and Mensah, I. A. (2020). Non-linear Nexus between CO2 Emissions and Economic Growth: A Comparison of OECD and B\&R Countries. Energy 212, 118637. doi:10.1016/ j.energy.2020.118637

Toader, E., Firtescu, B., Roman, A., and Anton, S. (2018). Impact of Information and Communication Technology Infrastructure on Economic Growth: An Empirical Assessment for the EU Countries. Sustainability 10, 3750. doi:10.3390/su10103750

Tyworth, M. (2014). Organizational Identity and Information Systems: How Organizational ICT Reflect Who an Organization Is. Eur. J. Inf. Syst. 23, 69-83. doi:10.1057/ejis.2013.32

Vural, G. (2020). Renewable and Non-renewable Energy-Growth Nexus: A Panel Data Application for the Selected Sub-saharan African Countries. Resour. Pol. 65, 101568. doi:10.1016/j.resourpol.2019.101568

Wang, J., Dong, X., and Dong, K. (2021a). How Renewable Energy Reduces CO2 Emissions? Decoupling and Decomposition Analysis for 25 Countries along the Belt and Road. Appl. Econ. 53, 1-17. doi:10.1080/00036846.2021.1904126

Wang, J., Jiang, Q., Dong, X., and Dong, K. (2021b). Decoupling and Decomposition Analysis of Investments and CO2 Emissions in Information and Communication Technology Sector. Appl. Energ. 302, 117618. doi:10.1016/ j.apenergy.2021.117618

Wang, Z., Danish, B. Z., Zhang, B., and Wang, B. (2018). Renewable Energy Consumption, Economic Growth and Human Development Index in Pakistan: Evidence Form Simultaneous Equation Model. J. Clean. Prod. 184, 1081-1090. doi:10.1016/j.jclepro.2018.02.260

World Bank (2017). World Development Indicators 2017. Washington, DC.: World Bank.

Xie, F., Liu, C., Chen, H., and Wang, N. (2018). Threshold Effects of New Energy Consumption Transformation on Economic Growth. Sustainability 10, 4124. doi:10.3390/su10114124

Yahya, F., and Rafiq, M. (2020). Brownfield, Greenfield, and Renewable Energy Consumption: Moderating Role of Effective Governance. Energ. Environ. 31 (3), 405-423. doi:10.1177/0958305x19872936

Yumashev, A., Ślusarczyk, B., Kondrashev, S., and Mikhaylov, A. (2020). Global Indicators of Sustainable Development: Evaluation of the Influence of the Human Development Index on Consumption and Quality of Energy. Energies 13 (11), 2768. doi: $10.3390 /$ en 13112768

Zafar, Kamran Impact of Information Communication Technology on Economic Growth: Evidence from Asian Economies. Islamabad: master thesis from CUST.

Zafar, M. W., Shahbaz, M., Hou, F., Sinha, A., and Sinha, A. (2019). From Nonrenewable to Renewable Energy and its Impact on Economic Growth: The Role of Research \& Development Expenditures in Asia-Pacific Economic Cooperation Countries. J. Clean Prod. 212, 1166-1178. doi:10.1016/j.jclepro.2018.12.081

Zhang, L., Li, Z., Kirikkaleli, D., Adebayo, T. S., Adeshola, I., and Akinsola, G. D. (2021). Modeling CO2 Emissions in Malaysia: An Application of Maki Cointegration and Wavelet Coherence Tests. Environ. Sci. Pollut. Res. 28 (20), 26030-26044. doi:10.1007/s11356-021-12430-x

Conflict of Interest: The authors declare that the research was conducted in the absence of any commercial or financial relationships that could be construed as a potential conflict of interest.

Publisher's Note: All claims expressed in this article are solely those of the authors and do not necessarily represent those of their affiliated organizations or those of the publisher, the editors, and the reviewers. Any product that may be evaluated in this article or claim that may be made by its manufacturer is not guaranteed or endorsed by the publisher.

Copyright (C) 2021 Azam, Rafiq, Shafique, Yuan and Salem. This is an open-access article distributed under the terms of the Creative Commons Attribution License (CC $B Y)$. The use, distribution or reproduction in other forums is permitted, provided the original author(s) and the copyright owner(s) are credited and that the original publication in this journal is cited, in accordance with accepted academic practice. No use, distribution or reproduction is permitted which does not comply with these terms. 